\title{
Does Greenhouses Gases Emissions Reduction Harms Economic Growth? A Lesson from Togolese Economy
}

\author{
Mikémina Pilo \\ Faculté des Sciences Economiques et de Gestion (Fa.SEG), Université de Kara, Kara, Togo \\ Email: pilomikemina15@gmail.com
}

How to cite this paper: Pilo, M. (2017) Does Greenhouses Gases Emissions Reduction Harms Economic Growth? A Lesson from Togolese Economy. Modern Econo$m y, 8,1033-1044$.

https://doi.org/10.4236/me.2017.88071

Received: July 6, 2017

Accepted: August 5, 2017

Published: August 8, 2017

Copyright $\odot 2017$ by author and Scientific Research Publishing Inc. This work is licensed under the Creative Commons Attribution International License (CC BY 4.0).

http://creativecommons.org/licenses/by/4.0/

\section{c) (i) Open Access}

\begin{abstract}
The move towards lower greenhouses gases (GHGs) emissions as a solution to mitigate climate change is not costless. Focusing on Togolese economy, we assessed in this article the role played by the shift to renewable energy consumption path in the search for higher economic growth. Based on the Auto-Regressive Distributed Lagged (ARDL) model and with the help of time series data that cover the period 1983-2012, our estimates indicate that the effects of higher renewable energy consumption on per capita economic growth varies depending on time horizon. A $1 \%$ increase of renewable energy consumption reduces per capita economic growth by $2.33 \%$ in the short run while it boosts economic growth by $1.22 \%$ in the long run. These findings are partly explained by the high technological rigidity of the country. The message to be sold to policy makers is that switching from fossil energy technology to technology based on renewable energy is an expensive and time consuming process which is economically efficient only in the long run. Consequently, the country might need relatively considerable time to fully shift to a cleaner path in terms of carbon emissions mitigation. Thus, the country move towards lower GHGs emissions must be tactically managed and done progressively.
\end{abstract}

\section{Keywords}

ARDL Model, Renewable Energy, Togo

\section{Introduction}

The world faces today a common challenge which is climate warming and change. This challenge according to the Intergovernmental Panel on Climate Change (IPCC) is the results of GHG emissions recorded during the last century. 
Climate change is going to certainly delay the attempts made to achieve the Sustainable Development Goals (SDG) since it is predicted to affect all kind of human activities if no action is taken [1]. The negative effect of climate change is well documented by the scientific body and well known by the general public. Two ways exist to deal with climate change: (i) adaptation and (ii) mitigation. Adaptation allows human being to withstand the adverse effects of climate change while mitigation reduces the range of climate warming and change. The two options are not substitutable. Without controlling climate change, effective adaptation might be difficult to achieve. The IPCC stated that affordable global warming is guided by the threshold of $2^{\circ} \mathrm{C}$ in the increase of temperature. This means that adaptation policies should be accompanied by mitigation programs and actions.

However, contrary to adaptation which seems to record higher consensus, implementation of policies aiming to reduce greenhouse gases emissions seems to be more challenging. The recent USA withdrawal from Paris agreement on emissions reduction is an illustration. Some of the reasons against GHG emissions reductions is that curbing emission reduces number of jobs in the economy and slows down economic growth. Thus, poverty, unemployment and lower economic growth might be the likely outcome for countries which choose to reduce GHGs emissions. This debate has been taking place in higher emissions countries given that emission reduction has rarely been the agenda of developing countries. Today, with the increasing agreement that developing world will have crucial role to play in the move toward a world without anthropogenic climate change, it is necessary to document how costly will the shift to a lower emissions trend be in developing countries.

Among the strategies available for emissions reduction, one can cite renewable energy. Renewable energy has the potential to significantly curb GHGs emissions [2]. Indeed, renewable energy gives the opportunity to deal with a set of challenges including socioeconomic progress, energy security, climate change [3]. However, switching from fossil fuels to renewable energy might not be definitely costless. Thus, focusing on the Togolese economy, this study assesses the impact of renewable energy consumption growth on economic growth. This is to provide policy makers with scientific evidence that can be brandished during climate change negotiations.

The remainder of the paper presents the related review of literature, some stylized facts, the theoretical foundation of the study and discusses the best methodology to be employed given our dataset characteristics. The paper ends with concluding remarks.

\section{Related Review of Literature}

World energy consumption demand will continue increasing given the projections of future population trend [4]. Under energy production status-quo scenario, this means that energy production from fossil fuel will sharply increase rendering more challenging climate change mitigation. The search for solutions to 
climate change and means to increase energy supply have then raised specific attention to the renewable energies.

Renewable energy is energy that is collected from renewable resources, which are naturally replenished on a human timescale, such as sunlight, wind, rain, tides, waves, and geothermal heat [2]. Renewable energy often provides energy in four important areas: electricity generation, air and water heating or cooling, transportation and rural (off-grid) energy services [3].

Based on IEA's 2016 report, renewables contributed 19.2\% to humans' global energy consumption and $23.7 \%$ to their generation of electricity in 2014 and 2015 , respectively. This energy consumption is divided as $8.9 \%$ coming from traditional biomass, $4.2 \%$ as heat energy (modern biomass, geothermal and solar heat), $3.9 \%$ hydroelectricity and $2.2 \%$ is electricity from wind, solar, geothermal, and biomass. Worldwide investments in renewable technologies amounted to more than US $\$ 286$ billion in 2015, with countries like China heavily investing in wind, hydro, solar and biofuels [4]. As of 2015 worldwide, more than half of all new electricity capacity installed was renewable [5].

Economic scientists' interests has included recently the role played by the increasing trend of renewable energy consumption in the search for higher economic performances. Thus, several studies have tried to determine the relationship between renewable energy consumption and economic growth. These studies are however biased towards developed countries and come up with various results. [6] studied the impact of energy consumption on economic growth in Taiwan and found that there exist a relationships between the two economic variables. According to [5], as GDP grows, energy consumption increases in USA. Some studies however revealed that economic growth and energy consumption are rather independent. Such studies include [7], and [8]. Another group of authors such as [9] [10] [11] [12] and [13] support the positive impact of GDP growth on energy consumption. According to them, the more earning means increasing tendency to protect environment by the use of renewable energy while at the same time [14] findings indicated that there is negative relationship between economic growth and renewable energy except for the countries with low level of renewable energies.

The differences in the findings of these studies mean that one size does not fits all. Individual countries' economies specificities and resources endowment might count in the nature of the relationship between renewable energy consumption and economic growth.

\section{Evidence from Some Stylized Facts}

Looking at the records of energy consumption across African regions and over time reveals considerable differences in its composition. Based on the data from the World Bank, we noticed that Sub-Saharan Africa (SSA) consumed energy is mostly coming from renewable energy as indicated in Figure 1. Figure 1 depicts the share of renewable energy consumption dynamics in two African regions 


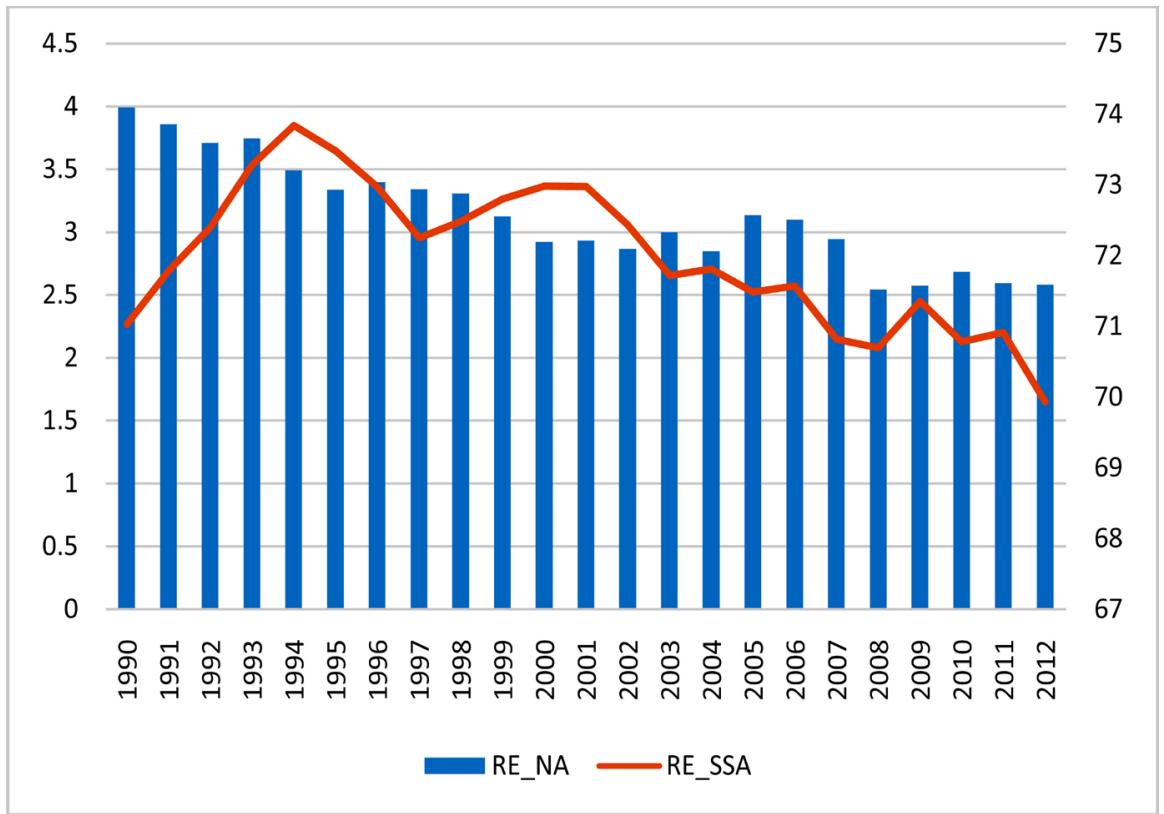

Source: Author base on WDI (2016) database.

Figure 1. Renewable energy consumption share dynamics in SSA and NA regions over 1990 to 2012.

that are North African (NA) region and SSA region over the period of 1990-2012 ${ }^{1}$. The right vertical axis represents the share of renewable energy consumption in SSA region's scale while the left one represents the renewable energy share in NA region's scale. The figure shows that SSA is an environmental friendly region since the lowest share of renewable energy consumption is above 70 percent. By contrast, NA region energy consumption appears to come mainly from nonrenewable sources. The highest share of renewable energy consumption recorded by this region is 4 percent. However, SSA seems not to be rewarded in terms of economic performances from these dynamics. SSA has been struggling to follow NA economic development path as shown in Figure 2 .

Looking at the Figure 2, one notices that economic growth in NA region has been clearly always greater than the one recorded in SSA over the period 1990-2012. Thus, it is difficult to decouple the high renewable energy share observed in SSA from this trend without a rigorous and solid empirical basis.

\section{Description of the Data}

The data used in this study comes from World Development Indicators (WDI) database [15]. The data covers the period 1983-2012. This period is determined by data availability. Four variables are considered: renewable energy consumption per capita in percentage of the total energy (re), GDP per capita growth (gdp), per capita exports measured in percentage of gdp per capita and capital stock per capita. In the empirical analysis all these variables are considered in ${ }^{1}$ The time period is determined by data availability. 


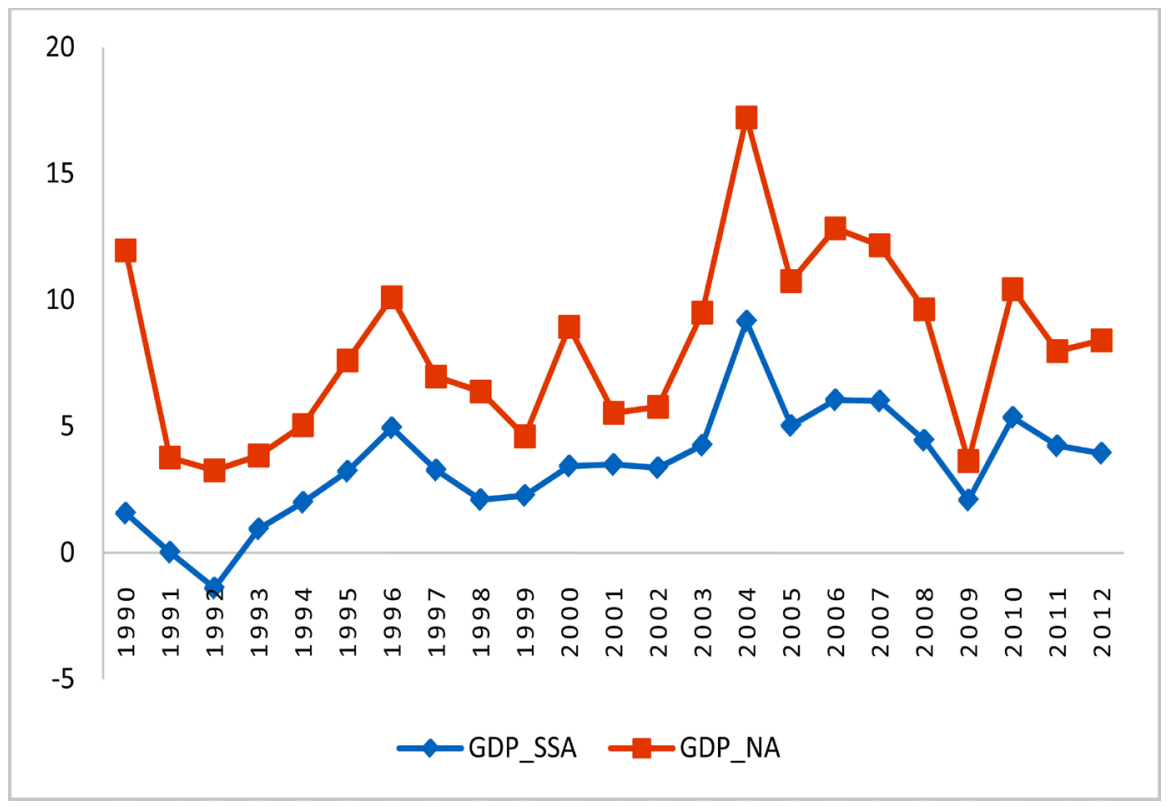

Source: Author based on WDI (2016) database.

Figure 2. GDP growth dynamics in SSA and NA regions.

logarithm in order to interpret their coefficient in terms of elasticity.

\section{Theoretical Foundation}

From economic literature relative to economic growth, four theories about the relationship between energy consumption and economic growth emerge. The first theory, known under the name of growth hypothesis argues that energy is one of the main factors of production in addition of labor and capital, and any increase in energy consumption leads to increase of production, hence economic growth. Thus, GDP growth are sensitive to energy policies. The second theory emerging from literature on the topic is conservative hypothesis. This hypothesis explains energy policies aiming to increase energy use efficiency by reducing energy consumption and energy waste. According to the third hypothesis known as neutrality hypothesis, energy consumption has little or no effect on economic growth. The feedback hypothesis is the last theory. It supports the idea that energy consumption and GDP growth supports each other. This means that there is two-way relationship between points gain in terms of GDP growth and the amount of energy consumed.

The specification of variables' dynamics is highly related to the sense of causality. Therefore, the causality test helps to empirically specify the model to be estimated. For instance, if the causality test indicates a feedback relationship between renewable energy and economic growth, a simultaneous equations model estimation might be useful. If by contrast, the results of the causality test show that there is only a unidirectional relationship between these two variables, OLS or ARDL model can be estimated depending of the level of stationarity of the considered variables. 


\section{Empirical Model and Estimation Technique}

\subsection{Granger Causality Test}

The Granger causality test is a statistical hypothesis test that can be used for determining whether a time series is useful in forecasting another. It was firstly proposed in 1969 by Clive Granger. From econometric point of view, granger test finds only predictive causality. We follow [16] test to assess the type of relationship that might exist between economic growth and renewable energy consumption in order to properly specify our empirical model (the two considered variables are taken in logarithm). The results presented in Table 1 below indicates that the null hypothesis that renewable energy consumption does not granger cause economic growth can be rejected while the reverse case that economic growth does not granger cause renewable energy consumption cannot be rejected. Thus, the relationship between economic growth and renewable energy can be considered as unidirectional. It follows that the empirical model to be estimated must be a one-way causality model.

\subsection{Empirical Model}

The traditional growth model developed by Solow [17] still widely used to explain economic growth of the countries. The approach was subsequently revised to incorporate Human Capital [18] and include environmental capital stock [19]. In its simplest form, an aggregate production function is set to explain the relationship between outputs of the economy and capital and labor. A relationship that can be denoted as:

$$
Y_{t}=A_{t} F\left(K_{t}, L_{t}\right)
$$

Reformulating the previous equation with the dependent variable express in terms of output per capita gives us Equation (2) below:

$$
y_{t}=a_{t} f\left(k_{t}\right)
$$

Adapting Equation (1) to the Togolese economy, we follow [20] to incorporate renewable energy consumption and exports. Exports can affect economic growth [21] as well as renewable energy consumption since the shift to renewable technologies might have considerable transitional costs. In the Equation (2), $y$ represents GDP per capita growth. Thus, the model to be estimated in this

Table 1. Granger Causality Wald tests.

\begin{tabular}{ccc}
\hline Equation & Excluded & Prob $>$ Chi2 \\
\hline Lngdp & Lnre & $0.072^{\star}$ \\
Lngdp & All & $0.072^{\star}$ \\
Lnre & Lngdp & 0.125 \\
Lnre & All & 0.125 \\
\hline
\end{tabular}

Source: Author estimates from Stata 15 base on WDI (2016) database; Note: ${ }^{\star}$ means significant at $10 \%$ threshold. 
study was formulated as:

$$
y_{t}=a_{t} f\left(k_{t}, r e_{t}, \exp _{t}\right)
$$

where re stands for renewable energy consumption and exp exportations. For the empirical application, we followed Cobb-Douglas functional form. Finally the function estimated is the one represented by the Equation (4) below.

$$
\operatorname{lngdp_{t}}=a_{0}+a_{1} \ln k_{t}+a_{2} \ln c e_{t}+a_{3} \ln \exp _{t}+\theta_{t}
$$

All the considered variables are taken in logarithm in order to interpret their coefficient in terms of elasticity as previously discussed. $\theta_{t}$ is the error term.

\subsection{Estimation Results and Discussions}

The choice of the best technique to fit the Equation (4) depends highly on the level of stationarity of the included variables. For instance, if all variables are stationary at level, Ordinary Least Square (OLS) estimates will be consistent. However, if some variables are $\mathrm{I}(0)$ and others $\mathrm{I}(1)$ the Auto-Regressive Distributed Lagged (ARDL) model will be the best to use rather than OLS technique. Thus, to avoid spurious estimates, we firstly run stationarity tests using Augmented Dickey Fuller test. The results are presented in Table 2 below.

Table 2 reveals that the variables Lnce and Lnexp are stationary at $1^{\text {st }}$ difference while the variables Lngdp and Lncap are stationary at level. It appears therefore that OLS estimates are biased and inconsistent. The auto-regressive distributed lagged (ARDL) model is consequently used to estimate the relationship between per capita gdp growth and selected independent variables. ARDL model has been developed by Pesaran, Shin and Smith in 2001 to estimates short and long terms dynamics between variables [22]. This means that the validity of ARDL model resides not only on the maximum level of stationarity of the variables included in the analysis (which might be at most I(1)), but also on the existence of short and long term dynamics. Thus, to verify whether there is any cointegration process between the dependent variables and the independent variables, we run Pearson-Shin-Smith bounds test [22] which results are presented in Table 3. The ARDL bounds test uses $\mathrm{F}$ and $\mathrm{t}$ statistics to test the null hypothesis that there is no levels relationship between the variables determining at the same time the optimum lagged level. Whether there exists a long term dynamics can also be established by this test.

The results of the bounds test confirm the existence of a long-run relationship

Table 2. ADF Unit root test results.

\begin{tabular}{cccc}
\hline Variables & Level & Test statistic & Critical level at $\mathbf{0 \%}$ \\
\hline Lnce & 1st diff & -3.27 & -3.22 \\
Lngdp & level & -5.79 & -2.62 \\
Lnexp & $1^{\text {st }}$ diff & -3.78 & -3.22 \\
Lncap & level & -3.81 & -2.62 \\
\hline
\end{tabular}

Source: Author from Stata 15 base on WDI (2016) database. 
Table 3. Pesaran-Shin-Smith bounds test.

\begin{tabular}{cc}
\hline Test statistics & Critical bounds values at $1 \%$ level \\
\hline $\mathrm{F}=10.05$ & {$[\mathrm{I}(0]=4.29 ;[\mathrm{I}(1)]=5.61$} \\
$\mathrm{t}=-5.87$ & {$[\mathrm{I}(0]=-3.43 ;[\mathrm{I}(1)]=-4.37$} \\
& $\mathrm{k}=3$ \\
\hline
\end{tabular}

$\mathrm{k}=$ number of non-deterministic regressors in long-run relationship; Source: Author from estimates in Stata 15 base on WDI (2016) database.

Table 4. Descriptive statistics.

\begin{tabular}{cccccc}
\hline Variables & Obs & Mean & Sd.Dev & Min & Max \\
\hline gdp & 30 & 2.49 & 5.92 & -15.10 & 14.98 \\
$\exp$ & 30 & 13.83 & 2.06 & 10.13 & 19.66 \\
cap & 30 & 17.17 & 3.71 & 10.91 & 28.23 \\
re & 30 & 29.94 & 3.65 & 23.05 & 38.21 \\
\hline
\end{tabular}

Source: Author estimates from Stata 2015 base on WDI (2016) database.

since F-statistic is superior to the critical bounds values and t-statistic inferior to the critical bounds level. The optimum lag level is 3. Consequently, we estimated ARDL.

\subsection{Descriptive Statistics of the Data}

We present the descriptive statistics of the utilized data in Table 4. Looking at that table we note that the average economic growth per capita (gdp) is 2.49 points with a minimum of -15.10 recorded in 1993. This minimum value is explained by the general strike declared non-negotiable launched that year as the result of democracy introduction in the country. As for renewable energy consumption per capita (re), it recorded an average value of 29.94 points. This value is encouraging and indicate the low level of industrial development of the economy. However, this good trend is likely to be reversed into a worrying trend with the increase industrialization of the country in the future if any industrial take off policy overlook GHGs emission reduction component. The exportation per capita average value recorded on the study period is 13.83 .

In addition to the previous descriptive statistics, we pursue our preliminary analysis by presenting the scatter plot between economic growth and renewable energy consumption. Figure 3 depicts that scatter plot between economic growth and renewable energy consumption. The analysis of that plot suggests a negative relationship between the two variables. This means that economic growth might be likely hampered by the shift from energy from fossil fuel to renewable energy. The correlation coefficient computed $(-0.30)$ seems to support this relationship. However, before drawing any policy implication base on this suggested relationship, one needs to deepen the analysis by the use of more sophisticated empirical tools. Thus, the following sections deal with this motivation. 


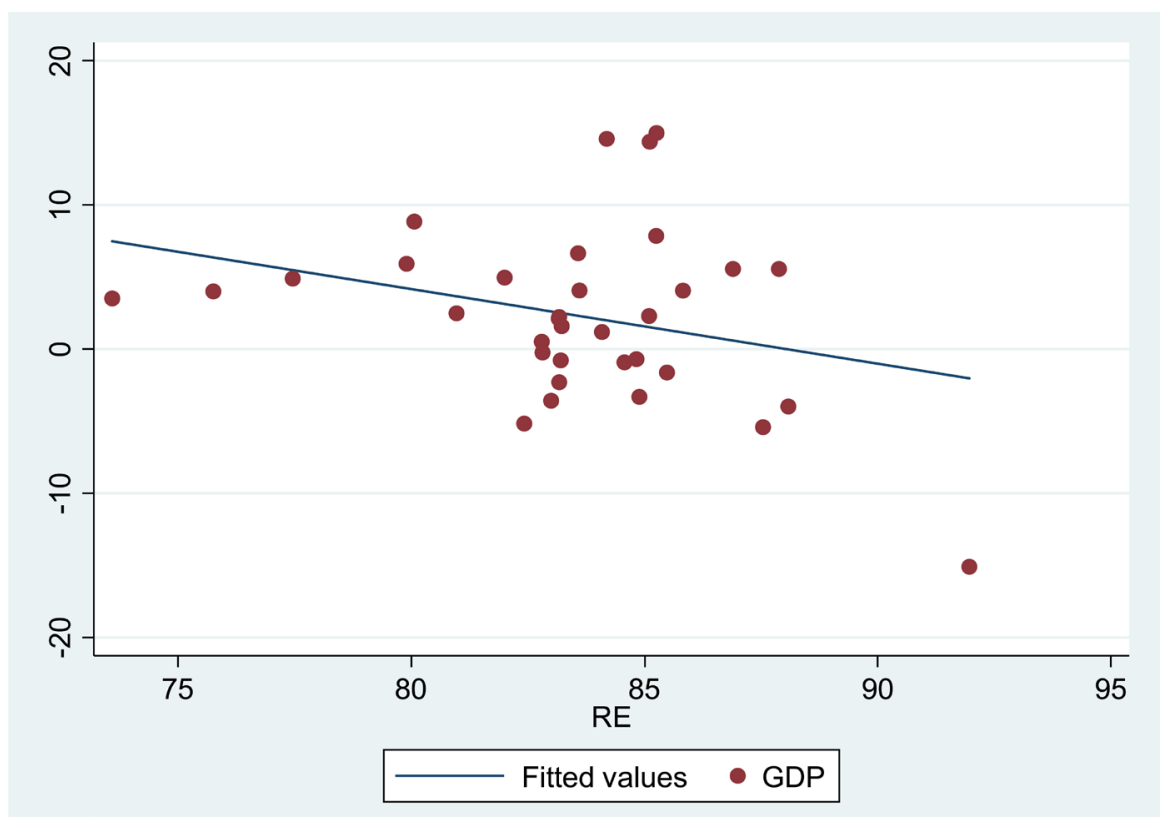

Source: Author from Stata 2015 base on WDI (2016) database.

Figure 3. Relationship between economic growth and renewable energy consumption.

Table 5. Results au the ARDL model estimates.

\begin{tabular}{|c|c|c|c|}
\hline Variables & Coef. & Std. Err. & $P>|t|$ \\
\hline $\mathrm{ADJ}$ & $-1.111^{\star * *}$ & 0.166 & 0.000 \\
\hline \multicolumn{4}{|c|}{ Long Run Equation } \\
\hline Lnexp & -0.011 & 0.049 & 0.818 \\
\hline Lnre & $1.228^{\star * *}$ & 0.406 & 0.007 \\
\hline Lncap & $0.119^{*}$ & 0.061 & 0.067 \\
\hline \multicolumn{4}{|c|}{ Short Run Equation } \\
\hline \multicolumn{4}{|l|}{ Lnexp } \\
\hline D1 & $0.271^{\star * *}$ & 0.098 & 0.007 \\
\hline $\mathrm{LD}$ & $0.166^{*}$ & 0.081 & 0.055 \\
\hline \multicolumn{4}{|l|}{ Lnre } \\
\hline D1 & $-1.549^{* * *}$ & 0.398 & 0.001 \\
\hline $\mathrm{LD}$ & $-1.194^{* * *}$ & 0.364 & 0.004 \\
\hline L2D & $-1.021^{* * *}$ & 0.349 & 0.009 \\
\hline L3D & $-1.145^{\star * *}$ & 0.338 & 0.003 \\
\hline \multicolumn{4}{|l|}{ Lncap } \\
\hline D1 & $-0.111^{\star *}$ & 0.048 & 0.032 \\
\hline Const. & $-6.366^{* * *}$ & 1.944 & 0.004 \\
\hline
\end{tabular}

Source: Author from estimates in Stata 15 base on WDI (2016) database.

Table 5 presents ARDL model estimation. The error correction coefficient is negative and significant. It has the value of -1.11 . The modelled process has a 
correction mechanism with the long-term unbalance adjustment speed equal to 2.11 (1-(-1.11). The overall results indicate that the determinants of economic growth in Togo and their relative importance change depending on the time horizon.

Focusing firstly on our main interest which is to detect the role plays by renewable energy in boosting economic growth, we realize that renewable energy has negative impact on economic growth in the short run. This negative impact turns to be positive in the long run. Indeed, in the short term, $1 \%$ increase of renewable energy consumption reduces the economic growth by $-2.33 \%$ ([-1.55-1.19-1.02-1.15]/2.11) in the short run. In the long run this impact turn to be positive with $1 \%$ increase of environmental friendly technologies use increasing GDP growth by $1.22 \%$. These results can be explained by the fact that technologies in Togo are so rigid that any abrupt change is less likely to be done efficiently. But as the time passes, adjustment are made to bring the new technologies on the efficient path. This is to say that the country might need considerable time to efficiently shift to lower carbon emissions technologies since this process is expensive and time consuming. These results are partially supported by the findings of the study by [23] and [24] which recognized that decoupling economic growth from fossil fuel is possible but with a speed which depend on how quick the combination of different forms of solar-based power, different forms of electric transport and different forms of urban fabric are happening.

Looking at the role played by classical economic growth determinants that are capital and exports, their sign would not have been predicted. Capital elasticity is negative in the short term which is contrary to the general conception. In the short term, capital intensity increase by $1 \%$ leads to the decrease of per capita GDP growth by $0.11 .12 \%$. This seemingly surprising findings is due to the fact that in the early of investment (the mean by which capital is increased) periods, the new capital stock is usually used below its best capacity of production and less efficiently. As the time goes the capital is used efficiently while its stock is being reduced by depreciation meaning that production output can be increased with a smaller stock of capital intensity. Thus, the capital intensity used here can thus be viewed as an inverse proxy of technical efficiency. In the long term however, capital intensity elasticity become positive since there might be no or lower technical inefficiency. The estimation results indicate also that higher exportations per capita measured as the percentage of GDP per capita can boost per capita GDP growth only in the short run. It effect in the long run can be assumed to be null since its long term coefficient appear to be not statically significant.

\section{Concluding Remarks}

Solutions to the challenges posed by climate change have been biased towards adaptation to climate change. Currently these solutions are being redesigned to include practical mitigation packages at the political and scientific level. The recent Paris agreement is an illustration at political level. To provide policy makers 
with useful scientific information on what is the cost of shifting to cleaner emissions path, we assessed in this study the role of renewable energy in boosting economic growth in Togo. Because of the level of stationarity of our variables which varies with the highest being one, and the cointegration between these variables, we used the Auto-Regressive Distributed Lagged (ARDL) model to assess the relationship between economic growth and renewable energy consumption.

From our findings, we concluded that the shift from current technologies to clean fuels and technologies hampers economic growth in Togo in the short run since a $1 \%$ increase of renewable energy consumption reduces per capita economic growth by $2.33 \%$. This is to say that shifting to a cleaner path has a cost in the short run. However, in the long term, higher effort to mitigate climate change in terms of access to environmental friendly technologies works as a solution to boost economic growth since $1 \%$ increase access to renewable energy technologies increases economic growth by $1.22 \%$. These findings can be explained by technological shifting's high costs as the result of high technological rigidity. The message to be sold to policy makers is that the country might need considerable time to fully shift to cleaner carbon emissions path. Thus, the country move towards lower greenhouses gases emissions must be tactically managed and done progressively.

\section{References}

[1] Intergovernmental Panel on Climate Change (2007) Impacts, Adaptation and Vulnerability. Contribution of Working Group II to the Fourth Assessment Report of the Intergovernmental Panel on Climate Change. Cambridge University Press, Cambridge.

[2] International Energy Agency (2016) World Energy Outlook. International Energy Agency, Paris.

[3] Stefan, D.A., Georgeta, V. and Stefan, C.G. (2017) Does Renewable Energy Drive Sustainable Economic Growth? Multivariate Panel Data Evidence for EU-28 Countries. Energies, 10, 1-21.

[4] Fotros, M.A. (2012) Impact of Economic Growth on the Consumption of Renewable Energy: A Comparative Study of Selected OECD and Non-OECD (Including Iran) Countries. Journal of Economic Research and Policies, 15, 81-98.

[5] Lee, C.C. (2007) The Impact of Energy Consumption on Economic Growth: Evidence from Linear and Nonlinear Models in Taiwan. Energy, 32, 2282-2294. https://doi.org/10.1016/j.energy.2006.01.017

[6] Abosedra, S.B. (1989) New Evidence on the Causal Relationship between United States Energy Consumption and Gross National Product. Energy and Development, 14, 285-292.

[7] Akarca, A.L. (1980) On the Relationship between Energy and GNP: A Reexamination. Energy and Development, 5, 326-331.

[8] Cheng, B. (1995) An Investigation of Cointegration and Causality between Energy Consumption and Economic Growth. Energy and Development, 21, 73-84.

[9] Huang, M.A. (2007) Is the Choice of Renewable Portfolio Standards Random? Energy Policy, 35, 5571-5575. https://doi.org/10.1016/j.enpol.2007.06.010 
[10] Sari, R. and Soytas, U. (2008) The Relationship between Disaggregate Energy Consumption and Industrial Production in the United States: An ARDL Approach. Energy Economics, 30, 2302-2313. https://doi.org/10.1016/j.eneco.2007.10.002

[11] Payne, J.E. (2010) Survey of the International Evidence on the Causal Relationship between Energy Consumption and Growth. Journal of Economic Studies, 37, 53-95. https://doi.org/10.1108/01443581011012261

[12] Yildirim, E., Sarac, S. and Aslan, A. (2012) Energy Consumption and Economic Growth in the USA: Evidence from Renewable Energy. Renewable and Sustainable Energy Review, 16, 6770-6774. https://doi.org/10.1016/j.rser.2012.09.004

[13] Naseri, S.F., Motamedi, S. and Ahmadian, M. (2016) Study of Mediated Consumption Effect of Renewable Energy on Economic Growth of OECD Countries. Procedia Economics and Finance, 36, 502-509. www.sciencedirect.com https://doi.org/10.1016/S2212-5671(16)30068-5

[14] Marques, A.F. (2010) A Quantile Approach to Identify Factors Promoting Renewable Energy in European Countries. Environmental and Resources Economics, 49, 351-366. https://doi.org/10.1007/s10640-010-9436-8

[15] WDI (2016) World Development Indicators Database. http://data.worldbank.org/products/wdi

[16] Granger, C.W.J. (1969) Investigating Causal Relations by Econometric Models and Cross-Spectral Methods. Econometrica, 37, 424-438. https://doi.org/10.2307/1912791

[17] Solow, R.M. (1956) A Contribution to the Theory of Economic Growth. The Quarterly Journal of Economics, 70, 65-94. https://doi.org/10.2307/1884513

[18] Romer, P. (1990) Endogenous Technological Change. Journal of Political Economy, 98, 71-102. https://doi.org/10.1086/261725

[19] Thampapillai, D.J. and Hanf, C.H. (2000) The Internalization of Environmental Capital Stocks into an Aggregate Cobb-Douglas Function. Economic Analysis and Policy, 30, 209-215. https://doi.org/10.1016/S0313-5926(00)50021-6

[20] Anaman, K.A. (2004) Determinants of Economic Growth in Brunei Darussalam. Journal of Asian Economics, 15, 777-796. https://doi.org/10.1016/j.asieco.2004.05.019

[21] Karras, G. (2001) Long-Run Economic Growth in Europe: Is It Endogenous or Neoclassical? International Economic Journal, 15, 63-76. https://doi.org/10.1080/10168730100080013

[22] Pesaran, H.A. (2001) Bounds Testing Approaches to the Analysis of Level Relationships. Applied Econometrics, 16, 289-326. https://doi.org/10.1002/jae.616

[23] Newman, P. (2017) Decoupling Economic Growth from Fossil Fuels. Modern Economy, 8, 791-805. https://doi.org/10.4236/me.2017.86055

[24] Apergis, N. and Danuletiu, D.C. (2014) Renewable Energy and Economic Growth: Evidence from the Sign of Panel Long-Run Causality. International Journal of Energy Economics and Policy, 4, 578-587. 
Submit or recommend next manuscript to SCIRP and we will provide best service for you:

Accepting pre-submission inquiries through Email, Facebook, LinkedIn, Twitter, etc. A wide selection of journals (inclusive of 9 subjects, more than 200 journals)

Providing 24-hour high-quality service

User-friendly online submission system

Fair and swift peer-review system

Efficient typesetting and proofreading procedure

Display of the result of downloads and visits, as well as the number of cited articles Maximum dissemination of your research work

Submit your manuscript at: http://papersubmission.scirp.org/

Or contact me@scirp.org 